\title{
How Much Have Variations in the Meridional Overturning Circulation Contributed to Sea Surface Temperature Trends since 1850? A Study with the EC-Earth Global Climate Model
}

\author{
TORBEN SCHMITH AND SHUTING YANG \\ Danish Meteorological Institute, Copenhagen, Denmark \\ EMILY GLEESON \\ Met Éireann, Glasnevin, Dublin, Ireland
}

TIDO SEMMLER

Alfred Wegener Institute, Helmholtz Centre for Polar and Marine Research Helmholtz, Bremerhaven, Germany

(Manuscript received 24 October 2013, in final form 5 May 2014)

\begin{abstract}
The surface of the world's oceans has been warming since the beginning of industrialization. In addition to this, multidecadal sea surface temperature (SST) variations of internal origin exist. Evidence suggests that the North Atlantic Ocean exhibits the strongest multidecadal SST variations and that these variations are connected to the overturning circulation.

This work investigates the extent to which these internal multidecadal variations have contributed to enhancing or diminishing the trend induced by the external radiative forcing, globally and in the North Atlantic. A model study is carried out wherein the analyses of a long control simulation with constant radiative forcing at preindustrial level and of an ensemble of simulations with historical forcing from 1850 until 2005 are combined. First, it is noted that global SST trends calculated from the different historical simulations are similar, while there is a large disagreement between the North Atlantic SST trends. Then the control simulation is analyzed, where a relationship between SST anomalies and anomalies in the Atlantic meridional overturning circulation (AMOC) for multidecadal and longer time scales is identified. This relationship enables the extraction of the AMOC-related SST variability from each individual member of the ensemble of historical simulations and then the calculation of the SST trends with the AMOC-related variability excluded. For the global SST trends this causes only a little difference while SST trends with AMOC-related variability excluded for the North Atlantic show closer agreement than with the AMOC-related variability included. From this it is concluded that AMOC variability has contributed significantly to North Atlantic SST trends since the mid nineteenth century.
\end{abstract}

\section{Introduction}

Since the beginning of the industrial era, it has been considered that human emissions of greenhouse gases have caused temperatures to rise in the lower troposphere and upper parts of the ocean due to a changed radiative balance (Arrhenius 1896). However, observations do not show a simple correspondence between the increase in the concentration of greenhouse gases

Corresponding author address: Torben Schmith, Danish Meteorological Institute, Lyngbyvej 100, Copenhagen 2100, Denmark. E-mail: ts@dmi.dk and the rise in surface temperature. While the concentration of greenhouse gases has been steadily rising since the beginning of industrialization, the global average surface temperature exhibits alternating periods of increase and periods of stall or even periods of slight decrease.

An analysis of observed SSTs back to the midnineteenth century reveals a multidecadal signal with its spatial signature concentrated near the North Atlantic Ocean (Deser and Blackmon 1993; Kushnir 1994; Schlesinger and Ramakutty 1994; Parker et al. 2007). This signal is overlaid on the overall global warming trend and is called the Atlantic multidecadal oscillation (AMO; 
Kerr 2000) or the Atlantic multidecadal variability (AMV), since it is not clear whether it is really an oscillation.

At present it is still under debate whether the AMO is externally forced (i.e., forced by anthropogenic and/or volcanic aerosols) or due to internal variability in the climate system, or a combination of the two. On the one hand, studies using coupled atmosphere-ocean GCMs claim that the full range of anthropogenic and natural external forcings can account for the gross features in the observed global temperature changes over the twentieth century while natural external forcings alone cannot (e.g., Broccoli et al. 2003; Stott et al. 2006; Knutson et al. 2006; Booth et al. 2012). On the other hand, Delworth and Mann (2000) showed evidence of an AMO-like variability mode by combining 300 years of observed and proxy temperatures with results from control experiments with a coupled climate model. Delworth and Knutson (2000) found that internal climate variability could have played a role in the observed warming in the 1930s-1940s centered around the North Atlantic. Also, the abovementioned study by Knutson et al. (2006) shows that internal variability might have played a role in the 1930s-1940s warming.

It is a challenge to separate the variations due to external forcing changes from internal variability during the twentieth century, since the variations caused by changes in the external forcing are most likely dominant, as demonstrated by studies based on Coupled Model Intercomparison Project (CMIP) phase 3 (CMIP3) twentieth-century historical simulations. Kravtsov and Spannagle (2008) subtracted the modeled ensemble mean SST from the observed SSTs and identified a strong multidecadal signal in the North Atlantic. Knight (2009) concluded that the observed SSTs fell outside the range spanned by an ensemble of modeled SSTs, from which he could isolate an internal variability component in the observations. Ting et al. (2009) applied analysis of variance (ANOVA) and signal-to-noise maximizing EOF analysis to modeled SSTs in order to separate externally forced variability from internal AMO-like variability.

A variant of the above type of work is to combine the historical simulations, where both forced and unforced variability is present, with unforced control simulations, where only unforced variability is present and should therefore be easier to detect. Swanson et al. (2009) isolated the regional signature of unforced SST variability from the CMIP3 control simulations, which was then removed from each historical simulation. DelSole et al. (2011) applied a novel statistical technique based on separation of variability by time scale to separate forced and internal variability.

While the details of the mechanisms behind the AMOlike low-frequency internal variability are still unclear and seem to vary between models, a common feature is stronger (weaker) than normal Atlantic meridional overturning circulation and meridional ocean heat transport associated with higher (lower) than normal SSTs in the North Atlantic and lower (higher) than normal SSTs in the South Atlantic. Polyakov et al. (2005) found coherent temperature and salinity variations in the entire North Atlantic Ocean in historical hydrographic observations that were out of phase for the $0-300-\mathrm{m}$ and 1000-3000-m layers of the ocean. This supports the notion that variations in the Atlantic meridional overturning circulation (AMOC) are contributing. Also, several model studies support the existence of such a "mode" involving the oceanic thermohaline circulation with a time scale of between 50 and 100 years (Vellinga and Wu 2004; Cheng et al. 2004; Delworth and Greatbatch 2000; Jungclaus et al. 2005; Flato et al. 2013, and others). The EC-Earth global coupled climate model used in the present study also exhibits similar variability (Wouters et al. 2012).

In aiming to separate internal variability and externally forced variations at multidecadal and longer time scales, we took a different approach to the work described above. We used a 543-yr-long control experiment with constant radiative forcing corresponding to preindustrial conditions. Our analysis showed that a large part of the multidecadal variability in the North Atlantic is related to the variations in the strength of the AMOC. Based on this, we were able to separate the AMOC-related variability from the SST data for an ensemble of historical simulations covering the period 1850-2005. Our approach has the twofold advantage of giving a more effective elimination of internal low-frequency variability and providing an insight into the physical mechanisms responsible for the internal variability.

The paper is structured as follows. The model and the experiments are described in section 2. In section 3 the internal SST variability at multidecadal to centennial time scales is analyzed while its relationship with the AMOC is treated in section 4. The contribution from internal variability to the late nineteenth- and twentiethcentury rise in the North Atlantic SST is described in section 5, and the contribution from AMOC is described in section 6. Section 7 contains a discussion and section 8 is a summary.

\section{Model and experiments}

The EC-Earth (version 2.3) global climate model used in this study consists of an atmosphere-land surface module coupled to an ocean-sea ice module (Hazeleger et al. 2010, 2012). The atmosphere component is the Integrated Forecasting System (IFS) cycle 31r1 with 
additions from a newer cycle, including the convection scheme from cycle 32r3. Physical processes are simulated at T159L62 resolution (corresponding to $1.125^{\circ}$ or approximately $125 \mathrm{~km}$ and with 62 vertical layers up to $5 \mathrm{hPa}$ ). The radiation scheme applies on a lower spectral resolution of T63. The land surface component is H-TESSEL (Balsamo et al. 2009).

The Nucleus for European Modelling of the Ocean (NEMO) version 2 (Madec 2008) is used for the oceansea ice component. NEMO is run on a stretched grid with three poles and a nominal horizontal resolution of $1^{\circ}(\sim 110 \mathrm{~km})$ and 42 vertical levels. A higher resolution of one-third of a degree is applied close to the equator. The sea ice component is the Louvain-la-Neuve Sea Ice Model (LIM) version 2 (Fichefet and Morales Maqueda 1997) with dynamics based on Hibler (1979) and thermodynamics based on Semtner (1976). The performance of NEMO in EC-Earth is described in Sterl et al. (2012).

The atmosphere-land surface module is coupled with the ocean-sea ice module using the Ocean Atmosphere Sea Ice Soil coupler (OASIS) version 3 (Valcke 2006).

The model simulations used in this work are part of an EC-Earth contribution to the CMIP phase 5 (CMIP5) protocol (Taylor et al. 2012). The model was spun up for 1100 years in order to reach a quasi-stationary state. The ocean was initialized with temperature and salinity fields from the World Ocean Atlas climatology (Conkright et al. 2002) and 40-yr European Centre for MediumRange Weather Forecasts (ECMWF) Re-Analysis (ERA-40) data for 1 January 1979 were used to initialize the atmosphere. Following the spinup simulation, a 543-yr-long control simulation (CTL) representing preindustrial climate conditions was carried out. Greenhouse gas and aerosol concentrations as well as solar irradiance at the top of the atmosphere (no volcanic forcing) have been kept constant at 1850 levels (Meinshausen et al. 2011) during both spinup and CTL. This preindustrial control simulation was used to launch an ensemble of "historical" simulations using starting conditions from the control simulation separated in time. The five historical simulations (HIS1-HIS5) are
TABLE 1. Overview of CMIP5 experiments with the global coupled climate model EC-Earth used in this study.

\begin{tabular}{|c|c|c|c|}
\hline Acronym & Forcing & $\begin{array}{c}\text { Length } \\
\text { (yr) }\end{array}$ & $\begin{array}{c}\text { Start year } \\
\text { (CTL) }\end{array}$ \\
\hline CTL & Constant, preindustrial & 543 & \\
\hline HIS1 & Historical, 1850-2005 & 156 & 2130 \\
\hline HIS2 & ، & “ & 2235 \\
\hline HIS3 & “ & “ & 2100 \\
\hline HIS4 & “ & “ & 2280 \\
\hline HIS5 & “ & “ & 2300 \\
\hline
\end{tabular}

forced with varying historical radiative forcing from 1850 to 2005 including changes in greenhouse gas concentrations, man-made and volcanic aerosol concentrations, and solar irradiance. Table 1 summarizes the model experiments used in this study.

Initial inspection of the results from the preindustrial control experiment showed a general cooling of the ocean surface in the range of -0.17 to $0.06 \mathrm{~K}_{\text {century }}{ }^{-1}$ and a slowdown of the AMOC around $0.15 \mathrm{~Sv}$ century ${ }^{-1}$ $\left(1 \mathrm{~Sv} \equiv 10^{6} \mathrm{~m}^{3} \mathrm{~s}^{-1}\right)$ because the control experiment CTL had not been in total equilibrium with the preindustrial radiative forcing conditions. Therefore, the SSTs from the control experiment were detrended in each grid point according to

$$
\operatorname{SST}^{\prime}(t)=\operatorname{SST}(t)-\alpha_{0}\left(t-t_{0}\right)
$$

where $\operatorname{SST}^{\prime}(t)$ is the detrended SST, $\alpha_{0}$ is the linear trend determined by a linear regression of the entire control experiment, and $t_{0}$ is the starting time of the control experiment.

Each historical experiment is the continuation of the control experiment from a starting date $t_{\text {start }}$ but with varying forcing for the historical period (i.e., 1850 and onward). Therefore, we presume that the background trend of the control experiment is also present in each of the historical runs and we thus perform detrending as

$$
\operatorname{SST}^{\prime}(t)=\operatorname{SST}(t)-\alpha_{0}[\underbrace{(t-1850)}_{\text {Time elapsed in historical exp }}+\underbrace{\left(t_{\text {start }}-t_{0}\right)}_{\text {Time elapsed in control exp }}] .
$$

The Atlantic meridional overturning streamfunction was detrended in a similar way.
After detrending as described above, to eliminate any background trends from the analysis, the long-term 


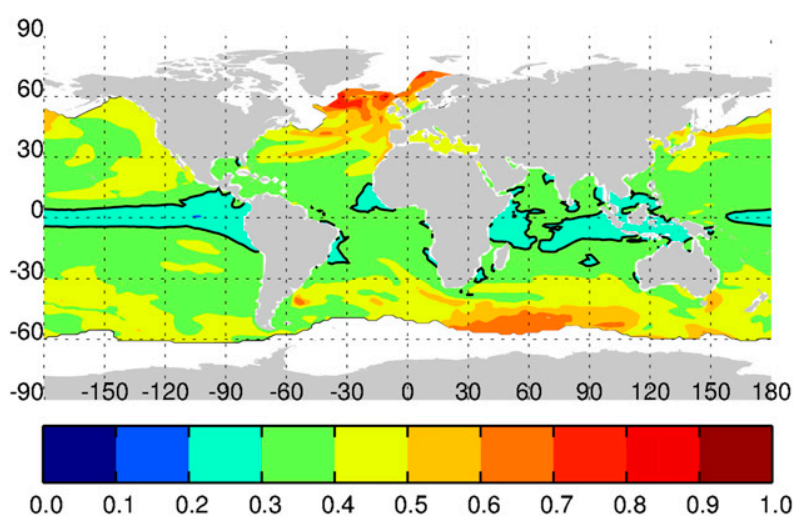

FIG. 1. Ratio of the standard deviation of low-pass filtered (11-yr running mean) SST anomalies to annual mean SST anomalies, calculated from the preindustrial control simulation (CTL). The black contour shows where the ratio equals $1 / \sqrt{11}$ (see text for further explanation). Areas where sea ice occurs are masked out.

annual cycle was removed from both control and historical experiments, yielding monthly anomalies of SST and AMOC for further analysis.

\section{Internal variability in SSTs at multidecadal to centennial time scales}

In this section we analyze the preindustrial control simulation (CTL) described in the previous section in order to get an insight into the natural SST variability patterns in the EC-Earth model.

In Fig. 1, we show the geographical distribution of the ratio of the standard deviation of the multidecadal (11-yr running mean) SST anomalies to the standard deviation of the annual SST anomaly variations. The parts of the ocean where sea ice occurs have been masked out because the SST variability is difficult to interpret in such areas. As an indicative "null hypothesis" we have contoured where the ratio is $1 / \sqrt{11}=0.3$ corresponding to the variance being distributed equally over all frequencies.

The highest values of this ratio are found in parts of the North Atlantic along with parts of the Southern Ocean, which therefore stand out as areas with a large fraction of multidecadal variability. Apart from these areas, the extratropical basins have moderate ratios, while rather low ratios are found in the tropics.

Further insight can be obtained by plotting time series of the annual SST anomalies, averaged over selected geographical regions, as shown in Fig. 2, with 11-yr running means overlaid to emphasize multidecadal variations. These multidecadal SST anomaly variations averaged over the North Atlantic are in the range of $\pm 0.2 \mathrm{~K}$ or more, while the amplitude of these variations is slightly smaller averaged over the North Pacific, and the typical time scale is also shorter. The SST anomalies have smaller amplitudes over tropical areas, with shorter time scales. All of this is as expected from the results presented in Fig. 1.

We estimate the power density spectra of these time series (Fig. 3). They all have the characteristic negative slope for high frequencies and the flattening out for lower frequencies, which is typical of ocean variables and is a sign of temporal correlation. The spectra for the tropics have a "shoulder" at the decadal or shorter time scale. The tropical Pacific and Atlantic differ in that the first has excess power at multiyear frequencies, most likely due to ENSO variability. Comparing the spectra for the North Atlantic and the North Pacific, we note that they both have shoulders in their spectra at multidecadal time scales. For longer time scales (i.e., lower frequencies), the North Atlantic has the largest variance, well above the variance of all of the other basins. Thus, the conclusion obtained via Fig. 1 that the North Atlantic stands out as having a large portion of variability at multidecadal and longer time scales is also supported by the spectral analysis of individual ocean basins.

\section{Relationship between SST variability and the Atlantic meridional overturning circulation}

As described in the introduction, many studies show that a large portion of the SST variability in the North Atlantic at multidecadal and longer time scales is related to variations in the Atlantic meridional overturning circulation. We will systematically investigate this relationship in the EC-Earth preindustrial control experiment, in particular whether the relationship depends on the time scale.

We define the strength of the AMOC as the maximum value of the Atlantic meridional overturning streamfunction near $30^{\circ} \mathrm{N}$. Defined in this way, the average strength of the overturning in the preindustrial control simulation is around $16 \mathrm{~Sv}$. Annual anomalies from this value are shown in Fig. 4. These anomalies typically vary between $\pm 1 \mathrm{~Sv}$ on multidecadal time scales, which dominates the time series. The power spectrum of this series (not shown) has a negative slope for high frequencies and a flattening out at a multidecadal to centennial time scale.

Many of these AMOC anomalies, such as the large negative anomaly around model year 2400 , can be immediately connected to the negative anomaly in North Atlantic average SSTs (Fig. 2, top). However, the large negative SST anomaly in the Northern Pacific around model year 2500 does not seem to have any corresponding feature in the AMOC series. Inspired by this, 

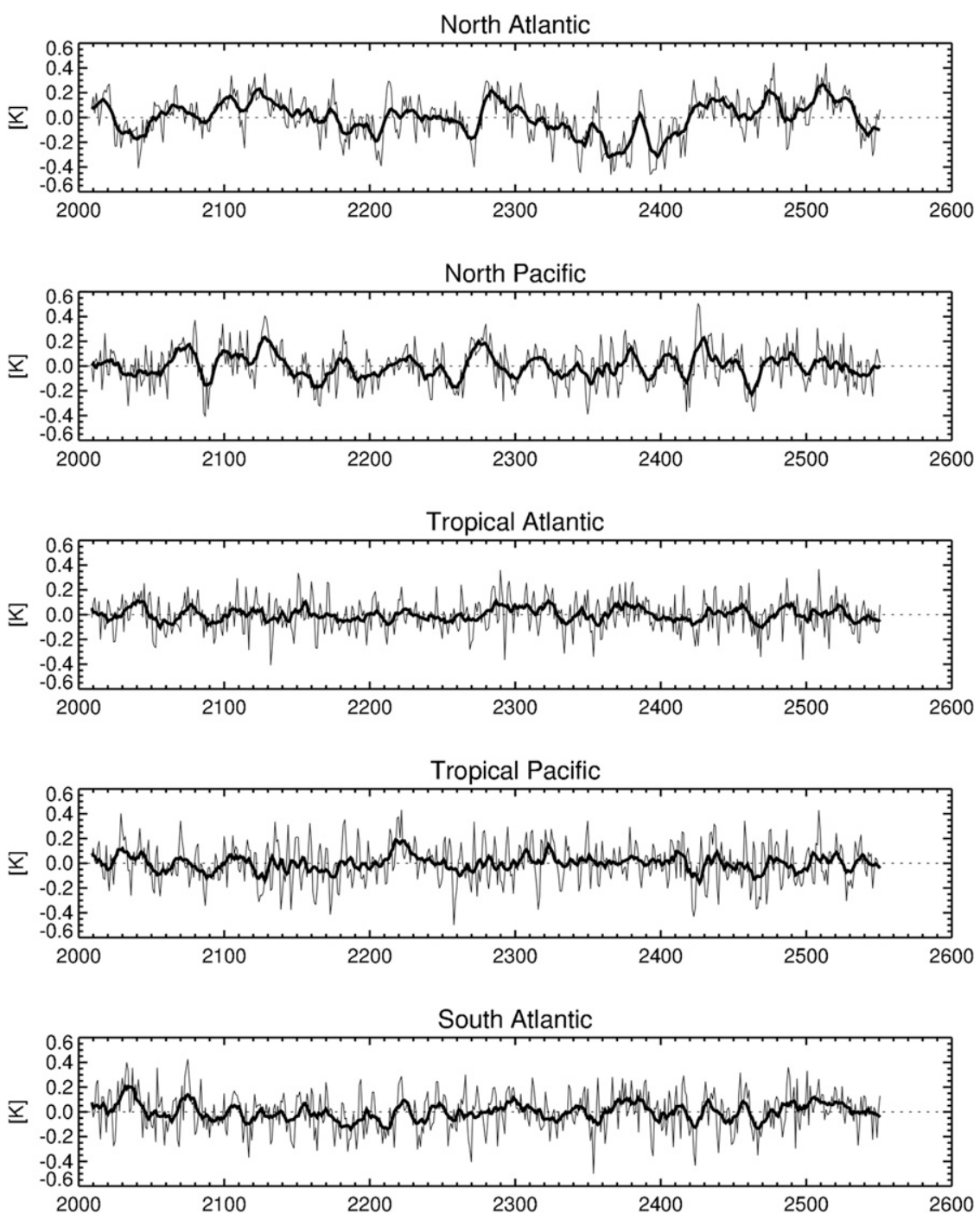

FIG. 2. Time series of annual mean SST anomalies averaged over different ocean basins. Thick curves are 11 -yr running means. North Atlantic limits are defined as $30^{\circ}-70^{\circ} \mathrm{N}, 70^{\circ} \mathrm{W}-$ $20^{\circ} \mathrm{E}$; North Pacific as $30^{\circ}-70^{\circ} \mathrm{N}, 100^{\circ} \mathrm{E}-120^{\circ} \mathrm{W}$; tropical Atlantic as $15^{\circ} \mathrm{S}-15^{\circ} \mathrm{N}, 70^{\circ} \mathrm{W}-20^{\circ} \mathrm{E}$; tropical Pacific as $15^{\circ} \mathrm{S}-15^{\circ} \mathrm{N}, 110^{\circ} \mathrm{E}-90^{\circ} \mathrm{W}$; and South Atlantic as $30^{\circ}-15^{\circ} \mathrm{S}, 70^{\circ} \mathrm{W}-20^{\circ} \mathrm{E}$.

we conducted a more rigorous statistical analysis of the relationship between SST anomalies in different ocean basins and anomalies in the AMOC.

The method we applied is coherency analysis, which can be thought of as a frequency-dependent correlation analysis of two time series. The coherency is a complexvalued quantity, where the absolute value (usually taken as the squared coherency) reveals information about the similarity of the two series at the given frequency, while the complex phase of the coherency reveals information about the lag at which the correlation is largest (at the given frequency).

Figure 5 shows the squared coherency spectra between AMOC strength and basin-averaged SST anomalies. At high frequencies (short time scales) the values of the squared coherency are generally below 0.2 for all basins considered. At lower frequencies, there is a notable difference between the North Atlantic and the other basins considered. At frequencies around $0.03 \mathrm{yr}^{-1}$, corresponding to a time scale of about three decades, the squared coherency increases abruptly and approximately assumes a constant value of 0.6 for time scales of 30 years and longer, showing that on these time scales $60 \%$ of the SST variability can be explained by variations in the AMOC.

The strong relationship between the AMOC and the North Atlantic SST anomaly on multidecadal and longer time scales is confirmed by the correlation coefficient between the AMOC strength and SST anomalies for 


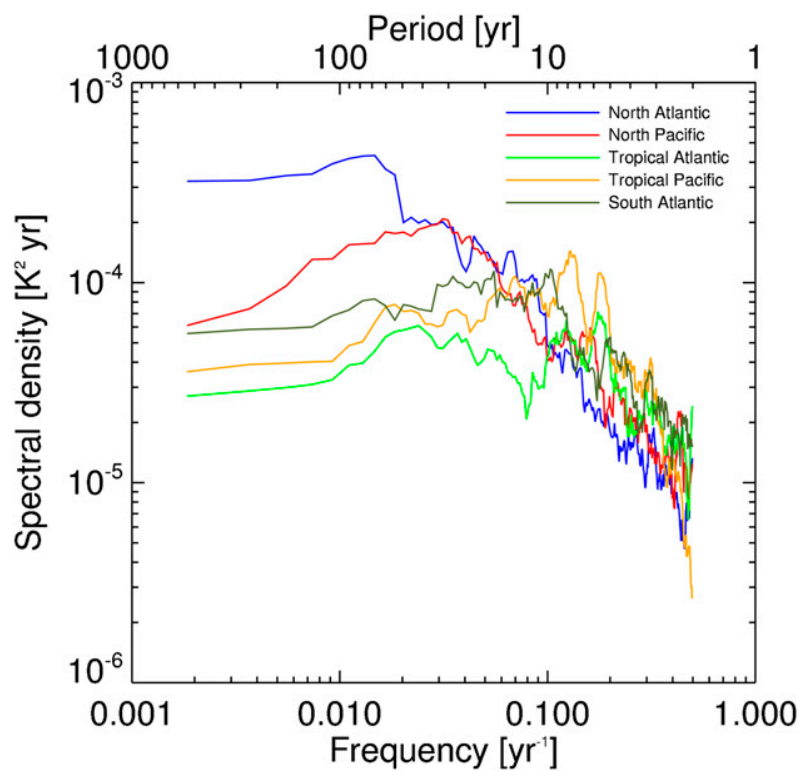

FIG. 3. Power density spectra of annual mean SST anomalies averaged over the different ocean basins defined in the caption of Fig. 2.

time scales longer than 30 years, shown in Fig. 6. In the North Atlantic, high correlations are dominant, whereas they are more sporadic in the northeast Pacific. In the tropics and in parts of the Southern Ocean we find values close to zero, while in other parts of the Southern Ocean we find multidecadal variability related to the AMOC (cf. Fig. 1). Globally, the correlation coefficient is 0.32 .

We determined the time lag at which the largest correlation between anomalies of the AMOC and the local

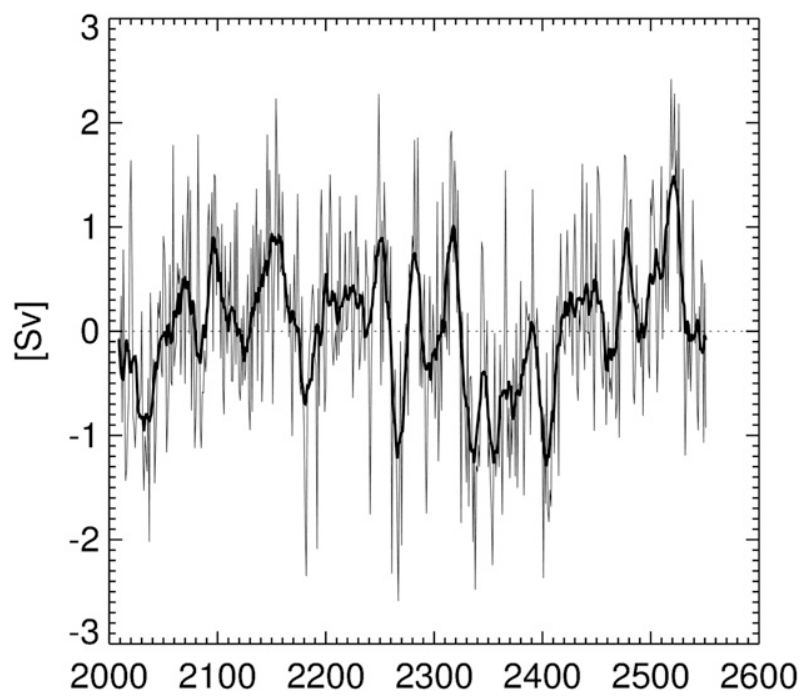

FIG. 4. Time series of annual anomalies in the AMOC strength, calculated as the maximum of the Atlantic Ocean overturning streamfunction near $30^{\circ} \mathrm{N}$. The thick curve is the $11-\mathrm{yr}$ running mean.

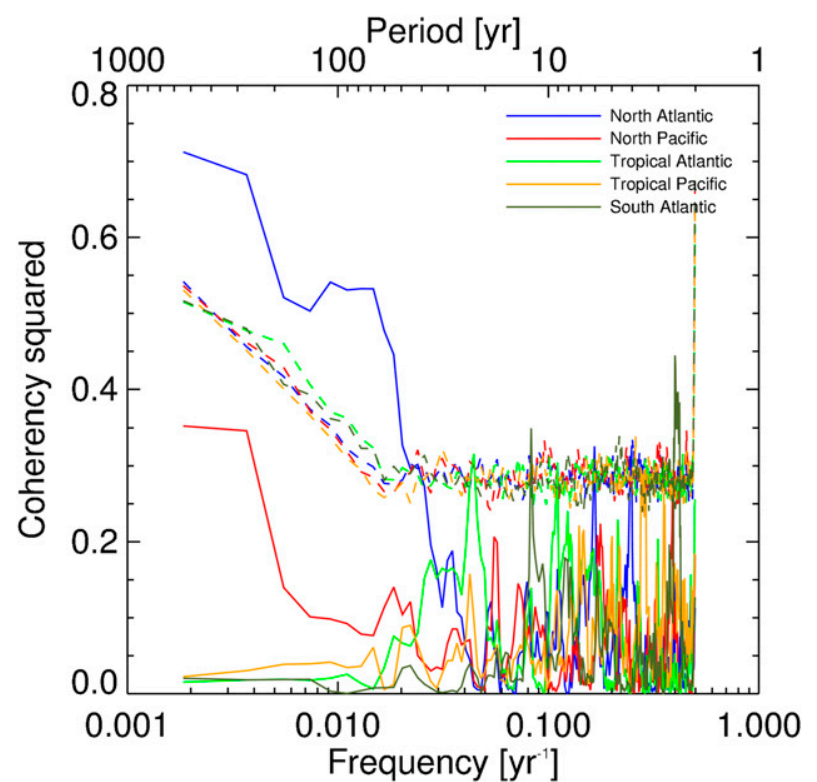

FIG. 5. Squared coherency spectrum between annual AMOC strength and basin-averaged annual SST anomalies. Dashed lines are $99 \%$ significant limits, obtained from Monte Carlo simulations.

SST occurs for each model grid point (not shown). In most of the North Atlantic the lag is numerically below 10 years. The lagged correlation coefficients were only slightly different from the instantaneous ones. Therefore, we do not take the time lags found into account and we regard the SST-AMOC relationship as instantaneous.

From the coherency analysis carried out above we conclude that for multidecadal and longer time, a relationship between anomalies in the AMOC strength and anomalies in the SST can be identified and that this relationship is strongest in the North Atlantic. Therefore, we determine a linear regression relation with constant

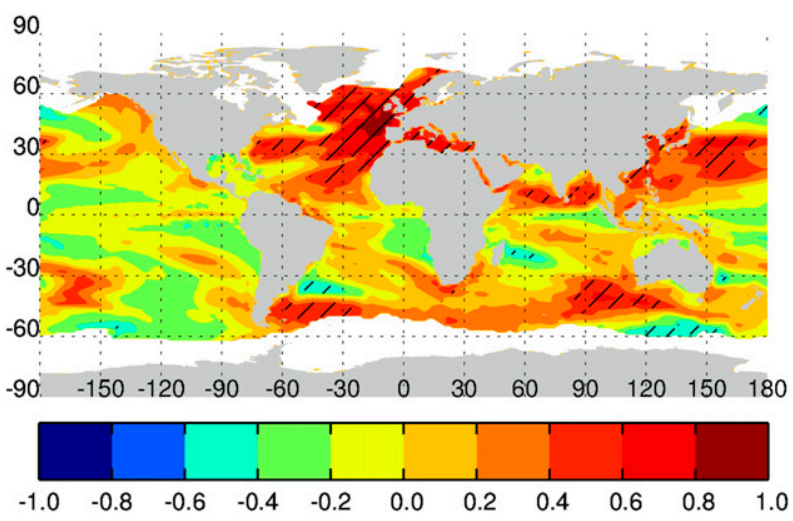

FIG. 6. Correlation coefficient between detrended and low-pass filtered (31-yr running mean) AMOC strength and SST anomalies. Hatching indicates areas where the correlation coefficient is significant at the $95 \%$ level. Significance levels are obtained by Monte Carlo simulation. 


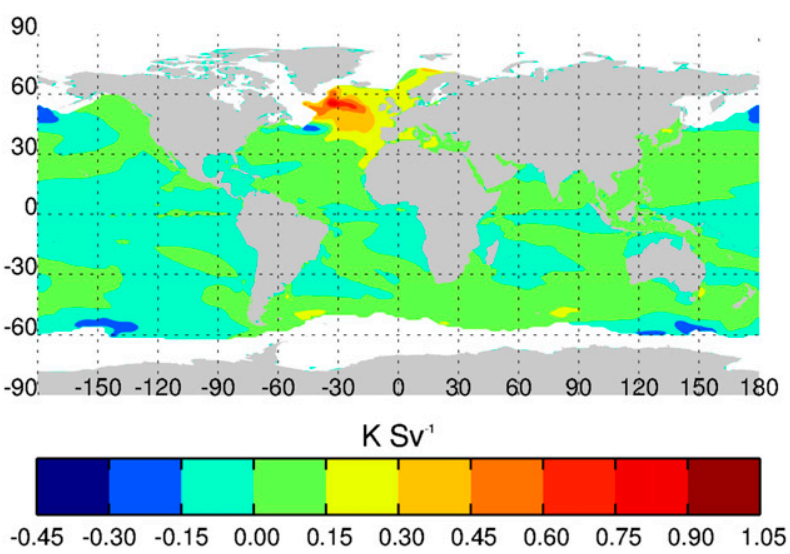

FIG. 7. Map of regression coefficient from SST anomalies regressed on AMOC anomalies by Eq. (1).

$\alpha_{x, y}$ and coefficient $\beta_{x, y}$ between these low-pass filtered variables for each model grid point $(x, y)$ :

$$
\overline{\operatorname{SSTA}}_{x, y, t}=\alpha_{x, y}+\beta_{x, y} \overline{\mathrm{AMOCA}}_{t}+\overline{\operatorname{SSTA}}_{x, y, t}^{\prime},
$$

where $\overline{\mathrm{SSTA}}_{x, y, t}$ and $\overline{\mathrm{AMOCA}}_{t}$ are the low-pass filtered SST and AMOC anomalies. The relationship (1) partitions the SST anomaly field in the term $\beta_{x, y} \overline{\mathrm{AMOCA}}_{t}$, which is the SST variability related to variations in AMOC, and a residual term $\overline{\mathrm{SST}}_{x, y, t}^{\prime}$, which is the SST anomaly field with the effect of the AMOC-related variability removed. This is analogous to the usually applied procedure for removing ENSO variability from the SST field.

The spatial distribution of the regression coefficient estimated from (1) is shown in Fig. 7. We find the numerically largest regression coefficients in the North Atlantic - that is, the largest average SST change for a 1-Sv change in AMOC strength, with values exceeding $0.4 \mathrm{~K} \mathrm{~Sv}^{-1}$ in many places.

To illustrate that the identified pattern of correlation coefficients has a basin-scale impact, we applied the model (1) to the control simulation and plotted area averages of the low-pass filtered SST anomalies for different basins and the corresponding AMOC-related multidecadal variability (Fig. 8). As expected, the North Atlantic basin stands out as having a large fraction of its multidecadal variability (correlation coefficient $=0.78$ ) explained by AMOC variations.

\section{The contribution from internal variability to SST rise in the North Atlantic in the late nineteenth century and the twentieth century}

From the analysis of the control simulation, we have seen that among the different basins of the World Ocean, the North Atlantic stands out as having the largest fraction of low-frequency variability and, furthermore, that this variability is related to variability in the AMOC. From this insight it is reasonable to ask to what extent these internal multidecadal variations could contribute significantly to changes in SSTs compared to the changes arising from increased radiative forcing through the period, globally and for the North Atlantic. A priori we would expect the effect to be larger in the North Atlantic than globally.

For each member of our ensemble of historical simulations, we calculate time series of area-averaged annual SST anomalies. These anomalies are shown, globally and for the North Atlantic, in Fig. 9 together with their ensemble mean. For comparison, we also show the corresponding time series calculated from observed SSTs (Kaplan et al. 1998). We expect that each of these members, in addition to the changes due to the external radiative forcing, contains SST variations due to internal variability. These variations are different for each ensemble member due to their different ocean initial conditions. Therefore, we expect the detailed SST development to be different ensemble members. This is also what we see, both globally and for the North Atlantic (Fig. 9).

Consider the global time series shown in Fig. 9 (top). A common feature of all ensemble members, and therefore also evident in the ensemble mean, is a generally rising average SST from the beginning of the twentieth century until around 1940. Thereafter, the average SST is almost constant but rises again from 1970. The observed SST has a qualitatively similar behavior. Since this behavior is common to all ensemble members it must be considered a result of the increase in external radiative forcing. There are also immediately evident shorter-term coolings common to all ensemble members and to observations. These follow major volcanic eruptions like the 1991 Pinatubo, the 1963 Agung, and the 1883 Krakatoa eruptions (not seen in observed SSTs).

Consider now the North Atlantic average SSTs shown in Fig. 9 (lower). The general SST rise throughout the twentieth century is also present here, but the short-term coolings connected to volcanic eruptions are not evident in all ensemble members. Furthermore, there are large and persistent differences between the different ensemble members. For instance, the ensemble member HIS1 is cooler than the ensemble mean by more than $0.5 \mathrm{~K}$ between 1915 and 1925, and has two decades of moderate positive SST anomalies (0.1-0.2 K) between 1940 and 1960. These anomalies are not evident in the global SST average. The spread among the members is also much larger than for the global SSTs. We note that the observed SSTs are enveloped by the SSTs of the ensembles.

From the above, we conclude that the EC-Earth model is able to produce low-frequency SST variability similar to that seen in observations. 
North Atlantic
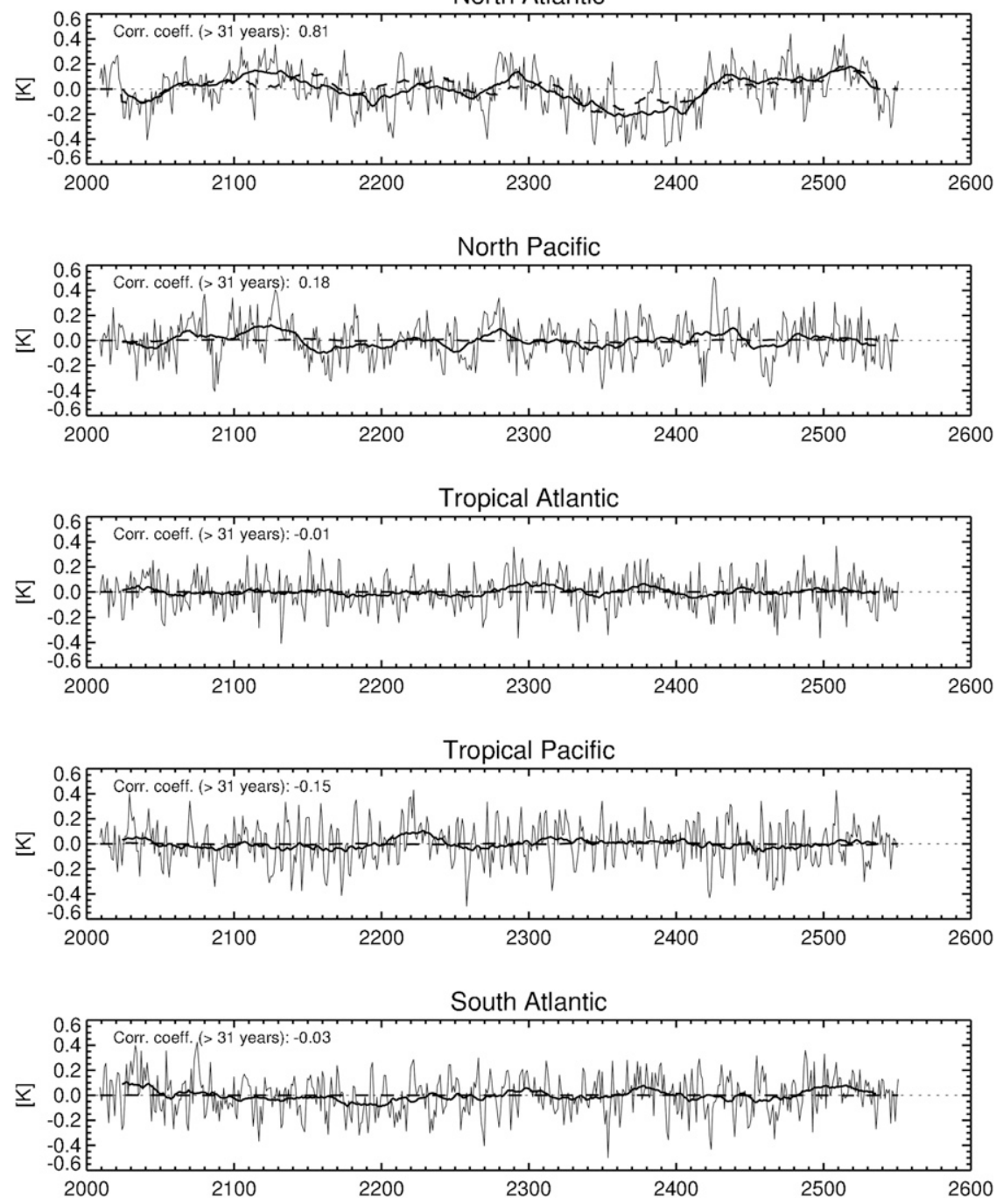

FIG. 8. Time series of area-averaged SST anomalies. Thick curves are 31-yr running means. Broken curves are the AMOC strength-related variations, calculated from (1). Also shown in each panel is the correlation coefficient between area-averaged SST anomaly and the AMOC strength for time scales longer than 31 years.

As a simple measure of whether internal variability has any significance, compared to the externally forced changes, we calculate the overall SST trend for each of the historical ensemble members, and for the observations (Fig. 10). The global SST trends calculated from the different ensemble members are all positive and cluster convincingly. We also note that the observed global trend lies outside the range of modeled trends, implying a general disagreement between model and observations. We will discuss this topic later in the paper.

The above is opposed to the North Atlantic SST trends, which are also all positive but with a large spread where a factor of more than 2 separates the two extreme trends.
We therefore conclude that the SST rise in the North Atlantic may have been quite heavily influenced by internal low-frequency variability, whereas globally the internal low-frequency variations have no detectable influence on the trend.

\section{The AMOC and its influence on the historical SST rise}

In Fig. 11 we show the strength (anomalies) of the AMOC as a function of year for the five historical simulations. All series exhibit a slowdown of around $1 \mathrm{~Sv}$ over the $150-y r$ period, but with multidecadal undulations on the order of $1-2 \mathrm{~Sv}$ (peak to peak). This is in 

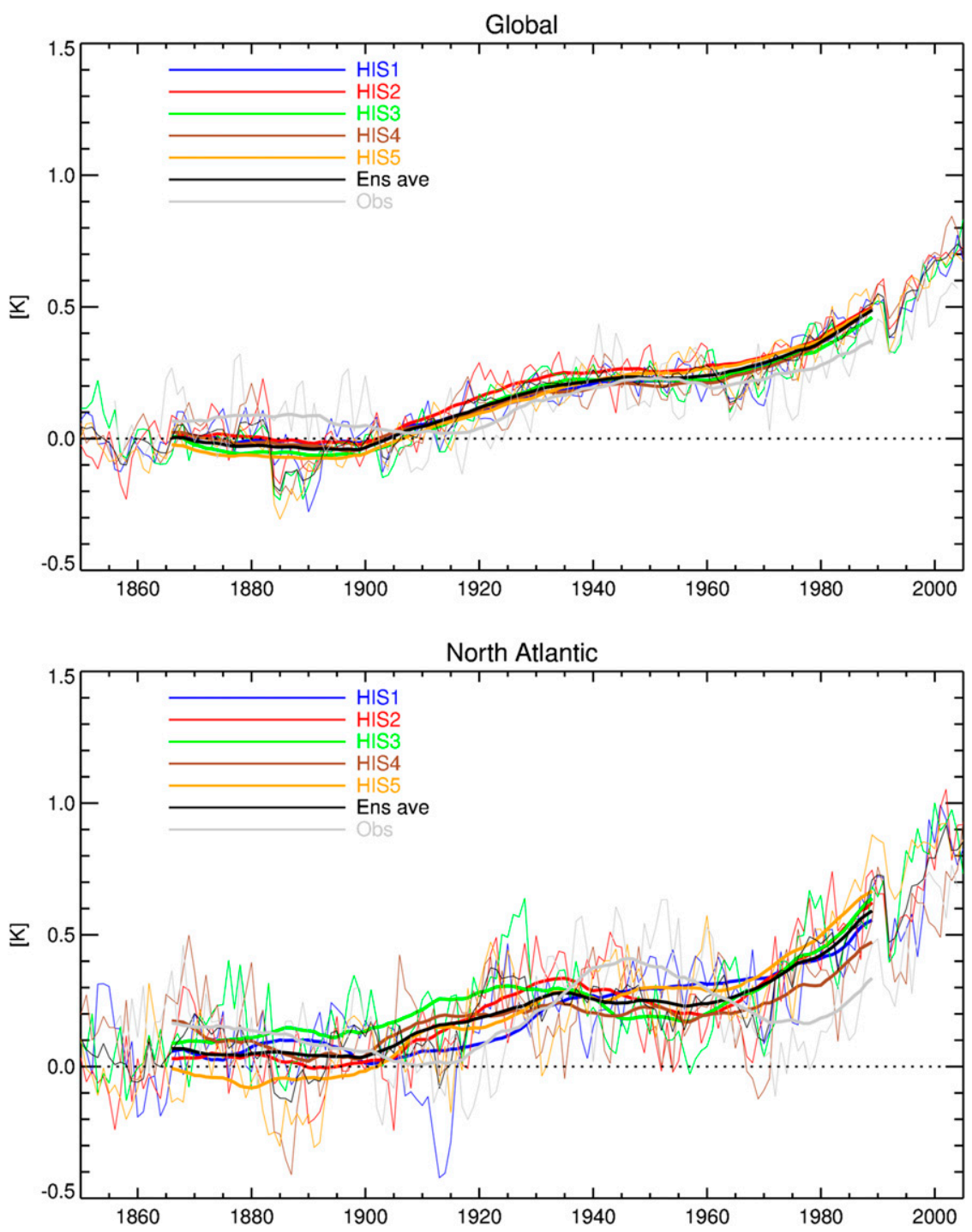

FIG. 9. Annual average of SST anomalies, (top) globally and (bottom) for the North Atlantic, from the historical simulations (colors) and from their ensemble average (black). Also shown are observed annual SST anomalies (gray), which are adjusted to match the ensemble average. Thick curves are 31-yr running means.

general agreement with other CMIP5 historical experiments (Collins et al. (2013).

The internal multidecadal variability previously identified in the unforced control experiment must also be present in the historical simulations. Therefore, we interpret the general slowdown as being a consequence of the external radiative forcing, while we regard the multidecadal undulations as internal variations analogous to the ones we found in the control experiment.

We can therefore isolate the internal variations signal in the historical AMOC series as follows. First we form the ensemble average of all historical AMOC series and this will then be our best estimate of the externally forced slowdown of the AMOC. This ensemble average is then subtracted from the AMOC series of each individual historical simulation and the resulting series are then the internal multidecadal variations of the AMOC in each historical series.

We then assume that the relationship (1), which was developed for the preindustrial control simulation, is also valid for the AMOC-related multidecadal variations in SST in the historical simulations, independent of any SST changes arising from the varying radiative external forcing. Therefore, we are able to subtract the AMOC-related SST anomaly change, given by (1), from the total SST anomaly, to obtain the AMOC-corrected SST anomaly as 

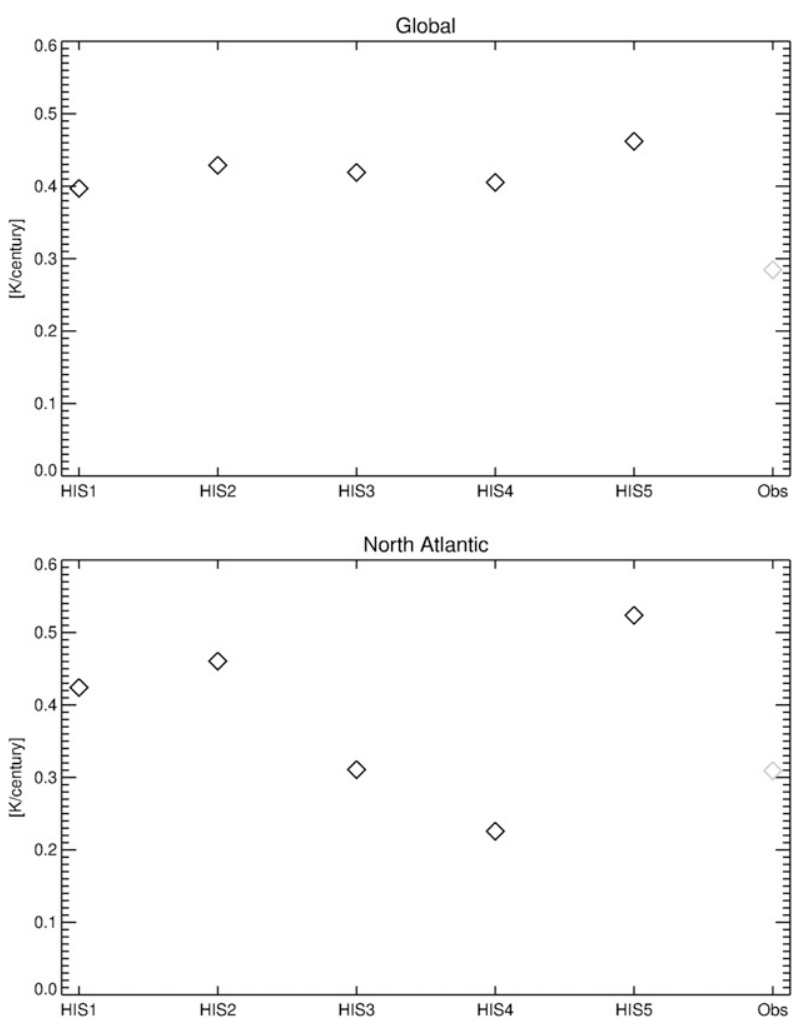

FIG. 10. Global and North Atlantic SST trend over the period 1850-2005 from the historical simulations and from observations.

$$
\overline{\mathrm{SST}}_{x, y, t}^{\mathrm{corr}}=\overline{\mathrm{SST}}_{x, y, t}-\alpha_{x, y}-\beta_{x, y} \overline{\mathrm{AMOC}}_{t} .
$$

Figure 12 shows the area-averaged AMOC-corrected SST anomalies (solid lines), together with the original SST series (broken lines). Visually, we can see indications of the influence of the AMOC on the North Atlantic SSTs since the full lines appear closer than the broken ones. A similar indication is not seen in the global series. We confirmed this by considering deviations from the ensemble mean of the original and AMOC-corrected series. For both groups of deviations, we then calculated their standard deviation jointly over time and across ensemble members (Table 2), globally and for the North Atlantic. Table 2 shows that globally (left column) we get no decrease in the standard deviation from the uncorrected to the AMOC-corrected values. Therefore, the global multidecadal variations are predominantly not associated with the AMOC. On the contrary, the overall decrease in standard deviation by the AMOC correction is substantial in the North Atlantic (right column). This shows that the AMOC has a nonnegligible effect on the twentieth-century SST development in the North Atlantic in our climate model experiments.
We also calculated twentieth-century trends from the AMOC-corrected series and these are shown in Fig. 13 together with the trends from the original series. We find that correcting for the AMOC influence gives a better agreement between North Atlantic SST trends among the different ensemble members. From a ratio between the largest and smallest North Atlantic SST trend in the original series of about 2.2, this ratio drops to less than 1.4 in the AMOC-corrected series.

This supports the validity of our assertion that AMOC variations have a noticeable effect on the North Atlantic SST trend during the twentieth century.

\section{Discussion}

When discussing the results obtained in our analysis it is important to remember that any studies involving the AMOC and its variations on multidecadal time scales necessarily rely heavily on model experiments. This is because, in contrast to SST, the temporal evolution of the AMOC is not directly measurable but must be indirectly estimated from observations. The hitherto most extensive monitoring of the AMOC is the UK-RAPID program (e.g., Cunningham et al. 2007) started in 2004 (i.e., with only less than 10 years of record). Alternatively, several ocean reanalysis products exist, where historical observations are assimilated into an ocean model, but their reproduction of the AMOC does not agree (Munoz et al. 2011).

It is also worth mentioning that Booth et al. (2012) presented a CMIP5 model study where the twentiethcentury North Atlantic SST variability was explained almost entirely by variations in external forcing. This is due to a more detailed description of aerosol physics. Booth et al.'s work evidently leaves little room for internal variability and is therefore in opposition to the present work. However, it has been criticized by Zhang et al. (2013) for being inconsistent with observed variations in ocean subsurface properties.

We note that the AMOC-SST relationship at multidecadal to centennial time scales explains about $60 \%$ of the total SST variance only. This is not surprising since the SSTs also exhibit weather-induced stochastic noise related to heating/cooling of the mixed layer. This type of variability has a characteristic time scale of weeks, and on annual and larger time scales it contributes to the SST power spectrum equally at all frequencies. Besides, other kinds of SST variability may be present, for example, variability connected to gyre circulations not considered here.

Reverting to the AMO signal and its discussion presented in the introduction, we note in Fig. 9 that the ensemble averages of both global and North Atlantic SSTs exhibit AMO-like features with almost constant 


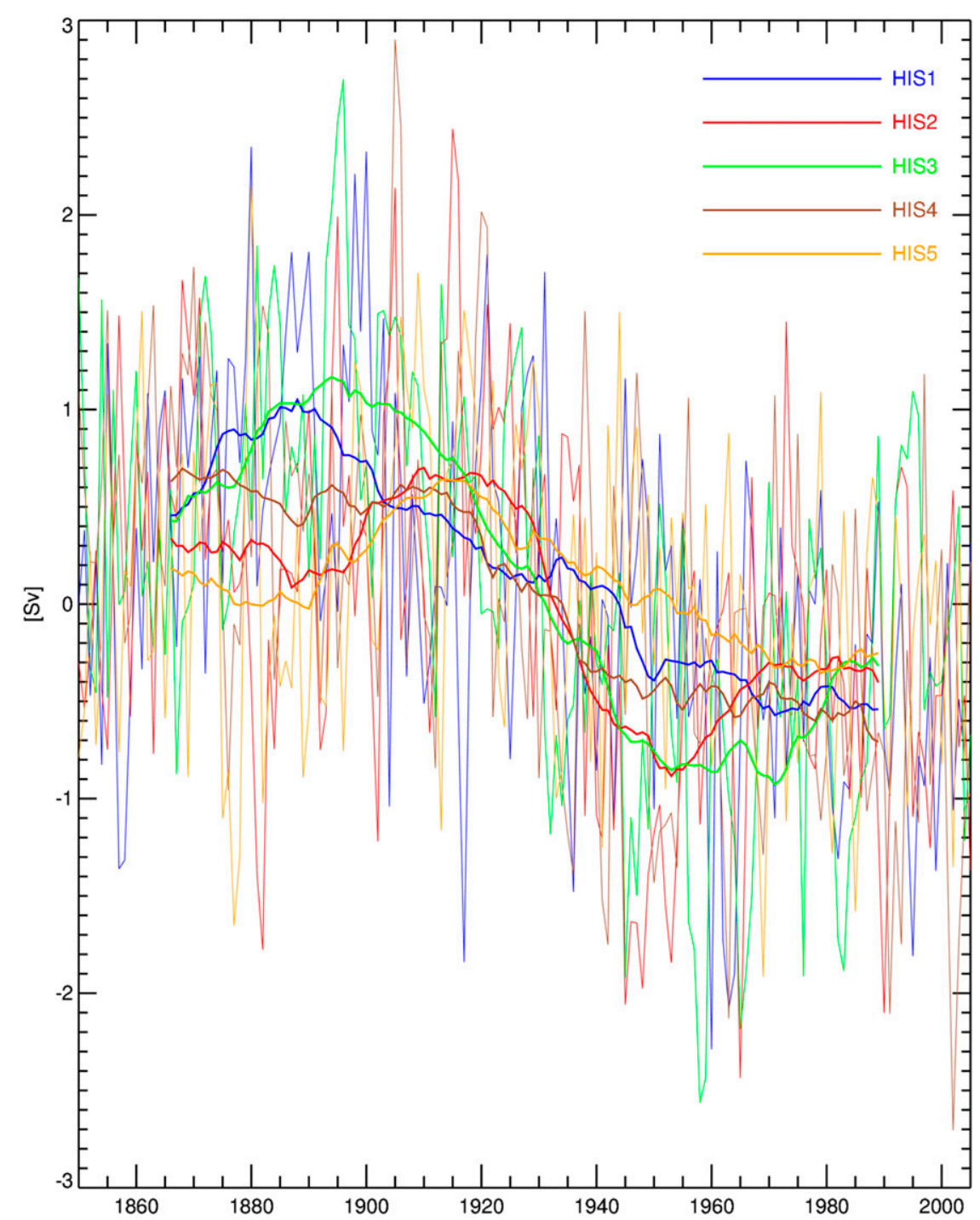

FIG. 11. Strength of the AMOC for the historical simulations. Thick curves are 31-yr running means.

temperatures between around 1940 and around 1970 . This means that at least part of the AMO is externally forced. On the other hand, the observed SST curves are very different from the ensemble averages and therefore internal variability must also contribute. This point cannot, however, be investigated further along the lines presented in this work, since the strength of the AMOC and its variations are not observed back in time.

When comparing the observed SST evolution with the model data, we notice that the observations seem to lie outside the range of the corresponding model ensemble members (Fig. 9). A reason could be a particularly strong AMOC variation, but there may be other reasons for the differences, for example an imperfect model and bias in the observed SSTs.
As mentioned earlier, the observed global SST trend lies outside the range spanned by the ensemble members (see Fig. 10). To this end we note that climate models are known to generally simulate too strong global warming in response to increases in greenhouse gas concentration in comparison to observations, in particular over the past 20 years (Fyfe et al. 2013). There have been several studies attempting to address this error but the causes are still unclear (Flato et al. 2013; Kosaka and Xie, 2013; Mauritsen et al. 2012). While the EC-Earth model used in this study demonstrates satisfactory radiative budget at the top of the atmosphere (Hazeleger et al. 2012), it suffers the same error of too strong a global warming response as other CMIP5 models. 

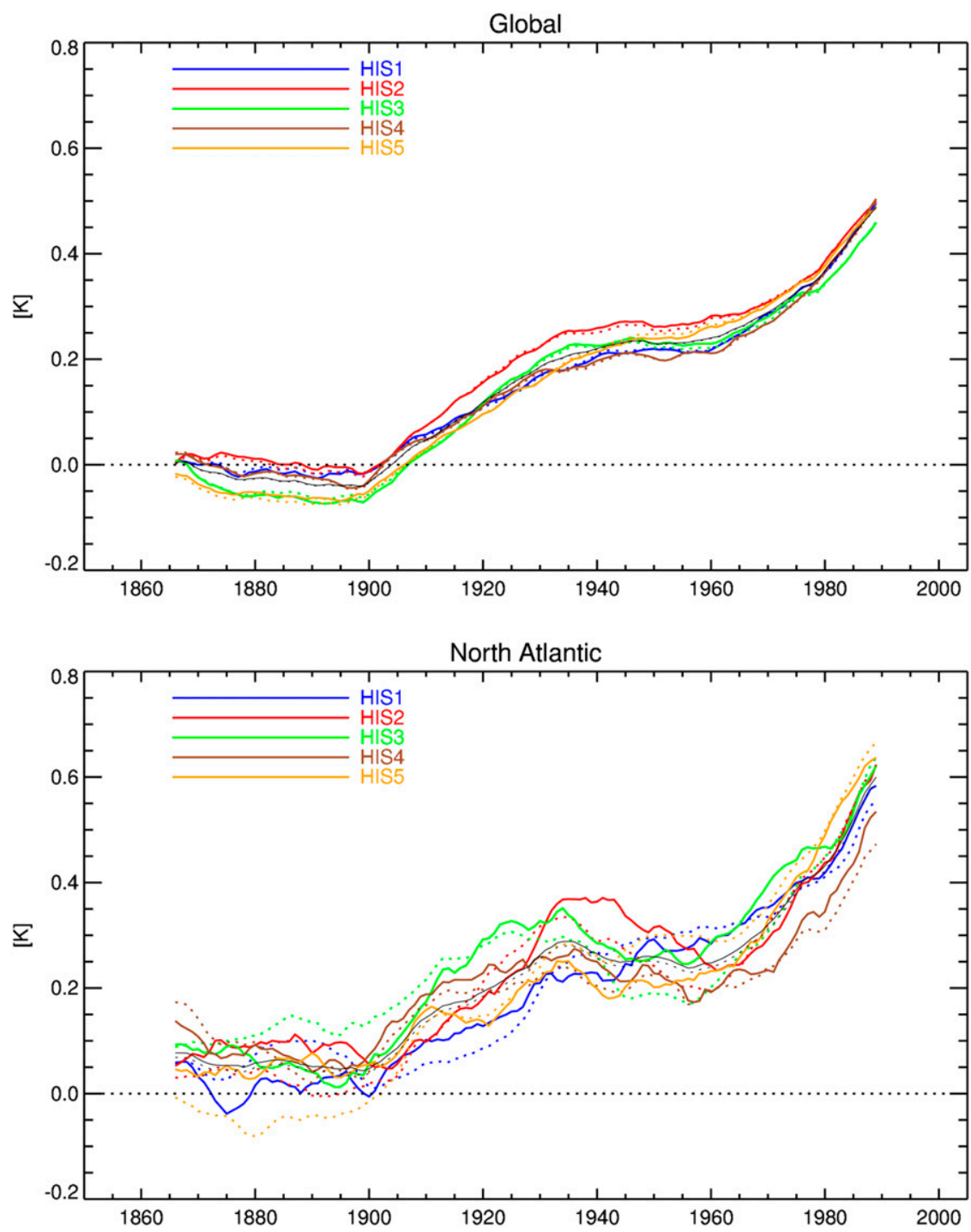

FIG. 12. Colored lines are AMOC-corrected SST anomalies for each ensemble member averaged (top) globally and (bottom) over the North Atlantic. Black line is the ensemble mean. Dotted lines are the original basin-averaged SST anomalies shown in Fig. 9.

In our analysis we assume that the AMOC is not interacting with the global radiative balance. That this is really the case in our control run is supported by the small correlation found between global average SST and AMOC on multidecadal time scales. This may be a deficit of the EC-Earth model and many other global climate models. A recent study using the ocean reanalysis showed that, while the global surface warming experienced a hiatus in the past decade, the radiative heating is redistributed into the deep ocean so that the warming continues at depths below $700 \mathrm{~m}$ (Balmaseda et al. 2013). This deep ocean warming seems to be resulting from the surface wind variability and relating to the weakening of MOC in recent years in the ocean reanalysis. This mechanism is not yet correctly represented in many models.

\section{Summary}

By the combined analysis of a preindustrial control simulation and historical simulations with external forcing,

TABLE 2. Standard deviation (K) calculated jointly over time and across ensembles, for the original and AMOC-corrected SST deviations from the ensemble mean.

\begin{tabular}{lcc}
\hline \hline & Global & North Atlantic \\
\hline Original & 0.021 & 0.061 \\
AMOC-corrected & 0.021 & 0.048 \\
\hline
\end{tabular}



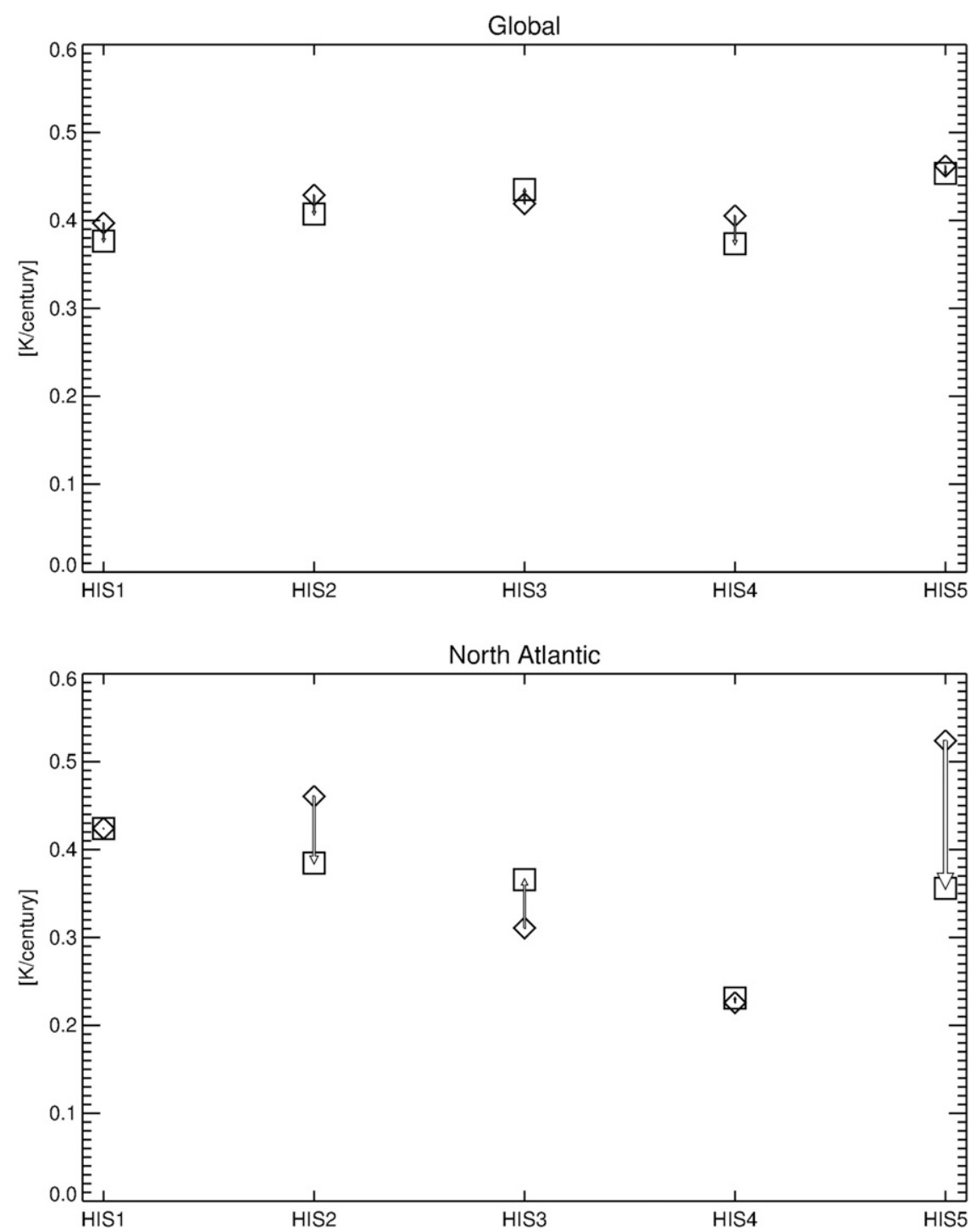

FIG. 13. Global and North Atlantic trend from the AMOC-corrected SST series over the period 1850-2005 from the historical simulations (squares).Trends from original series (see Fig. 10) shown for comparison (diamonds).

we have been able to draw important conclusions about trends in SSTs since the beginning of industrialization.

First, we demonstrated that the unperturbed climate of the control simulation exhibits internal variability with very different characteristics in the different ocean basins. We find that the North Atlantic stands out as having a large fraction of variability at multidecadal and longer time scales. Next we showed that on these time scales, there is a linear relationship with high correlation between SST variations averaged over the North Atlantic and variations in the AMOC.

Turning to the historical simulations, covering the period 1850-2005, we find a large spread in modeled SST trends for the North Atlantic, while we find large agreement for the global ocean as a whole. Under the assumption that the linear SST-AMOC relationship at long time scales also holds in the changing climate from 1850 onward, we are able to eliminate the effect of this variability and in doing this we diminish the spread of the North Atlantic SST trend.

We conclude that the internal multidecadal variations of the AMOC represent a significant contribution to modeled SST trends in the North Atlantic. Modeled trends are positive from all ensemble members so external forcing has a major role in shaping the North Atlantic SST trend. 
This study can be regarded as a first step using a new analysis method to separate multidecadal variability of internal origin from externally forced variability. Improvements could be made by applying the same method to the entire CMIP5 multimodel ensemble.

Acknowledgments. We would like to acknowledge the Irish Centre for High End Computing (ICHEC). This work was supported by the Danish Strategic Research Council under Contract 10-093903: North AtlanticArctic coupling in a changing climate: impacts on ocean circulation, carbon cycling, and sea ice (NAACOS).

Kaplan SST V2 data are provided by the NOAA/ OAR/ESRL PSD, Boulder, Colorado, USA, via their website at http://www.esrl.noaa.gov/psd/.

\section{REFERENCES}

Andronova, N. G., and M. E. Schlesinger, 2000: Causes of global temperature changes during the 19th and 20th centuries. Geophys. Res. Lett., 27, 2137-2140, doi:10.1029/2000GL006109.

Arrhenius, S., 1896: On the influence of carbonic acid in the air upon the temperature of the ground. London, Edinburgh, Dublin Philos. Mag. J. Sci., 41 (5th series), 237-275.

Balmaseda, M. A., K. E. Trenberth, and E. Källén, 2013: Distinctive climate signals in reanalysis of global ocean heat content. Geophys. Res. Lett., 40, 1754-1759, doi:10.1002/grl.50382.

Balsamo, G., P. Viterbo, A. Beljaars, B. van den Hurk, M. Hirschi, A. K. Betts, and K. Scipal, 2009: A revised hydrology for the ECMWF model: Verification from field site to terrestrial water storage and impact in the integrated forecast system. J. Hydrometeor., 10, 623-643, doi:10.1175/2008JHM1068.1.

Booth, B. B. B., N. J. Dunstone, P. R. Halloran, T. Andrews, and N. Bellouin, 2012: Aerosols implicated as a prime driver of twentieth-century North Atlantic climate variability. Nature, 484, 228-232, doi:10.1038/nature10946.

Broccoli, A. J., K. W. Dixon, T. L. Delworth, T. R. Knutson, R. J. Stouffer, and F. Zeng, 2003: Twentieth-century temperature and precipitation trends in ensemble climate simulations including natural and anthropogenic forcing. J. Geophys. Res., 108, 4798, doi:10.1029/2003JD003812.

Cheng, W., R. Bleck, and C. Rooth, 2004: Multi-decadal thermohaline variability in an ocean-atmosphere general circulation model. Climate Dyn., 22, 573-590, doi:10.1007/ s00382-004-0400-6.

Collins, M., and Coauthors, 2013: Long-term climate change: Projections, commitments and irreversibility. Climate Change 2013: The Physical Science Basis, T. F. Stocker et al., Eds., Cambridge University Press, 1029-1136.

Conkright, M. E., R. A. Locarnini, H. E. Garcia, T. D. Obrien, T. P. Boyer, C. Stephens, and J. I. Antonov, 2002: World Ocean Atlas 2001: Objective analyses, data statistics, and figuresCD-ROM documentation. National Oceanographic Data Center, Silver Spring, MD, 17 pp.

Cunningham, S. A., and Coauthors, 2007: Temporal variability of the Atlantic meridional overturning circulation at $26.5^{\circ} \mathrm{N}$. Science, 317, 935-938, doi:10.1126/science.1141304.

DelSole, T., M. K. Tippett, and J. Shukla, 2011: A significant component of unforced multidecadal variability in the recent acceleration of global warming. J. Climate, 24, 909-926, doi:10.1175/2010JCLI3659.1.
Delworth, T. L., and R. J. Greatbatch, 2000: Multidecadal thermohaline circulation variability driven by atmospheric surface flux forcing. J. Climate, 13, 1481-1495, doi:10.1175/ 1520-0442(2000)013<1481:MTCVDB > 2.0.CO;2.

—_, and T. R. Knutson, 2000: Simulation of early 20th century global warming. Science, 287, 2246-2250, doi:10.1126/ science.287.5461.2246.

, and M. E. Mann, 2000: Observed and simulated multidecadal variability in the Northern Hemisphere. Climate Dyn., 16, 661-676, doi:10.1007/s003820000075.

Deser, C., and M. L. Blackmon, 1993: Surface climate variations over the North Atlantic Ocean during winter: 1900-89. J. Climate, 6, 1743-1753, doi:10.1175/1520-0442(1993)006<1743: SCVOTN $>2.0 . \mathrm{CO} ; 2$.

Fichefet, T., and M. A. Morales Maqueda, 1997: Sensitivity of a global sea ice model to the treatment of ice thermodynamics and dynamics. J. Geophys. Res., 102, 12 609-12 646, doi:10.1029/ 97JC00480.

Flato, G., and Coauthors, 2013: Evaluation of climate models. Climate Change 2013: The Physical Science Basis, T. F. Stocker et al., Eds., Cambridge University Press, 741-866.

Fyfe, J. C., N. P. Gillett, and F. W. Zwiers, 2013: Overestimated global warming over the past 20 years. Nat. Climate Change, $\mathbf{3}$, 767-769, doi:10.1038/nclimate1972.

Hazeleger, W., and Coauthors, 2010: EC-Earth: A seamless Earth system prediction approach in action. Bull. Amer. Meteor. Soc., 91, 1357-1363, doi:10.1175/2010BAMS2877.1.

— , and Coauthors, 2012: EC-Earth V2.2: Description and validation of a new seamless Earth system prediction model. Climate Dyn., 39, 2611-2629, doi:10.1007/s00382-011-1228-5.

Hibler, W. D., 1979: A dynamic thermodynamic sea ice model. J. Phys. Oceanogr., 9, 815-846, doi:10.1175/1520-0485(1979)009<0815: ADTSIM>2.0.CO;2.

Jungclaus, J. H., H. Haak, M. Latif, and U. Mikolajewicz, 2005: Arctic-North Atlantic interactions and multidecadal variability of the meridional overturning circulation. J. Climate, 18, 4013-4031, doi:10.1175/JCLI3462.1.

Kaplan, A., M. Cane, Y. Kushnir, A. Clement, M. Blumenthal, and B. Rajagopalan, 1998: Analyses of global sea surface temperature 1856-1991. J. Geophys. Res., 103, 18567-18589, doi:10.1029/97JC01736.

Kerr, R. A., 2000: A North Atlantic climate pacemaker for the centuries. Science, 288, 1984-1985, doi:10.1126/science.288.5473.1984.

Knight, J. R., 2009: The Atlantic multidecadal oscillation inferred from the forced climate response in coupled general circulation models. J. Climate, 22, 1610-1625, doi:10.1175/ 2008JCLI2628.1.

Knutson, T. R., and Coauthors, 2006: Assessment of twentiethcentury regional surface temperature trends using the GFDL CM2 coupled models. J. Climate, 19, 1624-1651, doi:10.1175/ JCLI3709.1.

Kosaka, Y., and S.-P. Xie, 2013: Recent global-warming hiatus tied to equatorial Pacific surface cooling. Nature, 501, 403-407, doi:10.1038/nature12534.

Kravtsov, S., and C. Spannagle, 2008: Multidecadal climate variability in observed and simulated surface temperatures. J. Climate, 21, 1104-1121, doi:10.1175/2007JCLI1874.1.

Kushnir, Y., 1994: Interdecadal variations in North Atlantic sea surface temperature and associated atmospheric conditions. J. Climate, 7, 141-157, doi:10.1175/1520-0442(1994)007<0141: IVINAS $>2.0 . \mathrm{CO} ; 2$.

Madec, G., 2008: NEMO ocean engine. Note du Pole de modélisation de l'Institut Pierre-Simon Laplace 27, 217 pp. 
Mauritsen, T., and Coauthors, 2012: Tuning the climate of a global model. J. Adv. Model. Earth Syst., 4, M00A01, doi:10.1029/ 2012MS000154.

Meinshausen, M., and Coauthors, 2011: The RCP greenhouse gas concentrations and their extension from 1765 to 2300 . Climatic Change, 109, 213-241, doi:10.1007/s10584-011-0156-z.

Munoz, E., B. Kirtman, and W. Weijer, 2011: Varied representation of the Atlantic meridional overturning across multidecadal ocean reanalyses. Deep-Sea Res. II, 58, 1848-1857, doi:10.1016/j.dsr2.2010.10.064.

Parker, D., C. Folland, A. Scaife, J. Knight, A. Colman, P. Baines, and B. Dong, 2007: Decadal to multidecadal variability and the climate change background. J. Geophys. Res., 112, D18115, doi:10.1029/2007JD008411.

Polyakov, I. V., U. S. Bhatt, H. L. Simmons, D. Walsh, J. E. Walsh, and X. Zhang, 2005: Multidecadal variability of North Atlantic temperature and salinity during the twentieth century. J. Climate, 18, 4562-4581, doi:10.1175/JCLI3548.1.

Schlesinger, M. E., and N. Ramakutty, 1994: An oscillation in the global climate system of period $65-70$ years. Nature, $\mathbf{3 6 7}, 723$ 726, doi:10.1038/367723a0.

Semtner, A. J., Jr., 1976: A model for the thermodynamic growth of sea ice in numerical investigations of climate. J. Phys. Oceanogr., 6, 379-389, doi:10.1175/1520-0485(1976)006<0379: AMFTTG $>2.0 . \mathrm{CO} ; 2$.

Sterl, A., and Coauthors, 2012: A look at the ocean in the EC-Earth climate model. Climate Dyn., 39, 2631-2657, doi:10.1007/ s00382-011-1239-2.
Stott, P. A., G. S. Jones, J. A. Lowe, P. Thorne, C. Durman, T. C. Johns, and J. C. Thelen, 2006: Transient climate simulations with the HadGEM1 climate model: Causes of past warming and future climate change. J. Climate, 19, 2763-2782, doi:10.1175/ JCLI3731.1.

Swanson, K. L., G. Sugihara, and A. A. Tsonis, 2009: Long-term natural variability and 20th century climate change. Proc. Natl. Acad. Sci. USA, 106, 16120-16123, doi:10.1073/ pnas.0908699106.

Taylor, K. E., R. J. Stouffer, and G. A. Meehl, 2012: An overview of CMIP5 and the experiment design. Bull. Amer. Meteor. Soc., 93, 485-498, doi:10.1175/BAMS-D-11-00094.1.

Ting, M., Y. Kushnir, R. Seager, and C. Li, 2009: Forced and internal twentieth-century SST trends in the North Atlantic. J. Climate, 22, 1469-1481, doi:10.1175/2008JCLI2561.1.

Valcke, S., Ed., 2006: OASIS3 user guide. PRISM Tech. Rep 3, 64 pp. [Available online at http://www.prism.enes.org/Publications/ Reports/oasis3_UserGuide_T3.pdf.]

Vellinga, M., and P. Wu, 2004: Low-latitude fresh water influence on centennial variability of the thermohaline circulation. J. Climate, 17, 4498-4511, doi:10.1175/3219.1.

Wouters, B., D. Drijfhout, and W. Hazeleger, 2012: Interdecadal North-Atlantic meridional overturning circulation variability in EC-EARTH. Climate Dyn., 39, 2695-2712, doi:10.1007/ s00382-012-1366-4.

Zhang, R., and Coauthors, 2013: Have aerosols caused the observed Atlantic multidecadal variability? J. Atmos. Sci., 70, 1135-1144, doi:10.1175/JAS-D-12-0331.1. 